\title{
INVESTIGAÇÕES SOBRE A EXPERIÊNCIA EM ECOLOGIA PROFUNDA
}

\author{
Investigations about experience in deep ecology \\ Investigaciones sobre la experiencia en ecología profunda
}

\author{
Gabriela Gazola Brandão \\ Universidade Federal Fluminense
}

\begin{abstract}
Resumo
Este ensaio abre minhas investigações sobre aproximações e interfaces entre a ecologia profunda e a geografia humanista, objetivando um diálogo com minha área de formação e atuação, a arquitetura e o urbanismo. Diálogo pretendido por entender que a partir da arquitetura e do urbanismo se revela uma fenomenologia do habitar, e por considerar a arquitetura como expressão e continente do habitar, o qual abarca, dentre outras, as relações entre o homem e a Terra. Assumindo que esta relação perpassa a prática da arquitetura e do urbanismo, chegamos ao ponto em que a ecologia profunda dialoga e contribui para o referido campo, sobretudo, a partir do planejamento ambiental. Neste primeiro momento, trago aproximações do âmbito das experiências sensíveis, desveladas no diálogo entre geografia humanista e ecologia profunda, e encerro com algumas considerações formuladas a partir de minha experiência sensível em ecologia profunda e de meus estudos.
\end{abstract}

Palavras-chave: Ecologia profunda; Planejamento Ambiental; Experiência sensível.

\begin{abstract}
This essay opens my investigations on approximations and interfaces between deep ecology and humanist geography, aiming at a dialogue with my area of formation and performance, architecture and urbanism. Dialogue intended because the undestanding that from architecture and urbanism a phenomenology of dwelling is revealed, and considering architecture as an expression and continent of dwelling, which includes, among others, the relations between man and the Earth. Assuming that this relationship permeates the practice of architecture and urbanism, we reach the point where the deep ecology dialogues and contributes to the said field, above all, from the environmental planning. In this first moment, I bring approximations of the scope of the sensitives experiences, unveiled on the dialogue between humanist geography and deep ecology, and I close with some considerations formulated from my sensitive experience in deep ecology and my studies.
\end{abstract}

Keywords: Deep ecology; Environmental planning; Sensitive experience.

\section{Resumen}


Este ensayo abre mis investigaciones sobre aproximaciones e interfaces entre la ecología profunda y la geografía humanista, objetivando un diálogo con mi área de formación y actuación, la arquitectura y el urbanismo. Diálogo pretendido por entender que a partir de la arquitectura y del urbanismo se revela una fenomenología del habitar, y por considerar la arquitectura como expresión y continente del habitar, el cual abarca, entre otras, las relaciones entre el hombre y la Tierra. Asumiendo que esta relación atraviesa la práctica de la arquitectura y del urbanismo, llegamos al punto en que la ecología profunda dialoga y contribuye al referido campo, sobre todo, a partir de la planificación ambiental. En este primer momento, trago acercamientos del ámbito de las experiencias sensibles, desveladas en el diálogo entre geografía humanista y ecología profunda, y cierro con algunas consideraciones formuladas a partir de mi experiencia sensible en ecología profunda y de mis estudios.

Palabras clave: Ecología Profunda; Planificación Ambiental; Experiencia sensible.

\section{ABERTURAS}

Este ensaio abre minhas investigações sobre aproximações e possíveis interfaces entre a ecologia profunda e a geografia humanista, objetivando um diálogo com minha área de formação e atuação, a arquitetura e o urbanismo. Diálogo pretendido por entender que a partir da arquitetura e do urbanismo se revela uma fenomenologia do habitar, e por considerar a arquitetura como expressão e continente do habitar, o qual abarca, dentre outras, as relações entre o homem e a Terra. Assumindo que esta relação perpassa a prática da arquitetura e do urbanismo, chegamos ao ponto em que a ecologia profunda dialoga e contribui para o referido campo, sobretudo, a partir do planejamento ambiental. A princípio, vislumbro como prosseguimento deste ensaio o caminho de discutir uma proposta de planejamento ambiental que parta do mundo-vivido e da consciência ecológica - e não de paradigmas da ética ambiental ou do ambientalismo.

Como primeiro movimento, apresentarei neste ensaio aproximações do âmbito das experiências sensíveis, desveladas no diálogo entre geografia humanista e ecologia profunda, e encerrarei com considerações formuladas a partir de minha experiência sensível em ecologia profunda e de meus estudos em fenomenologia. O objetivo do presente texto não é discutir os princípios metodológicos, as proposições teóricas ou as bases conceituais da ecologia profunda, mas refletir sobre o que seria, no meu entendimento, sua essência - a experiência sensível.

\section{EXPERIÊNCIAS SENSÍVEIS: APROXIMAÇÕES}

A relação entre a abordagem de que se vale ecologia profunda e a abordagem fenomenológica está posta desde a origem: as inquietações que moveram seus propositores 
e que movem a quem por elas se interesse: a busca pela aproximação com o mundo-vivido e a experiência direta dos fenômenos. A relação foi também destacada por Nelson (2008, p. 206), que afirma que a ecologia profunda está fundada no método fenomenológico, e por Zimmerman, em diversos trabalhos que colocam em diálogo o pensamento de Martin Heidegger com a filosofia ambiental, sobretudo em sua obra Implications of Heidegger's Thought for Deep Ecology (1986).

A preocupação com e a valorização da experiência direta dos fenômenos são evidentes na ecologia profunda, sobretudo por sua proposta de experiências sensíveis, motivo maior de meu interesse e inquietações sobre o tema. A experiência sensível em ecologia profunda é proposta com objetivo de sentir a ecologia profunda em vez de apenas apreender intelectualmente seus princípios. Que é, exatamente o ponto que considero central na ecologia profunda, seu alicerce, e de onde podem partir suas maiores contribuições para diversos campos do conhecimento. O entendimento da ecologia profunda amplia-se na medida em que ela é entendida como ontológica, e não como um conjunto de princípios de ética ambiental ou ambientalismo.

Refiro-me como experiências sensíveis em ecologia profunda às chamadas vivências em ecologia profunda. Propor uma experiência sensível é um caminho bastante utilizado pelos estudiosos da ecologia profunda para que ela se faça compreender - ou melhor, experienciar - a quem se interesse. Nos cursos ofertados sobre o tema, a maior parte da carga horária é dedicada à proposta de experiências sensíveis - as vivências. Os proponentes, chamados facilitadores da vivência, conduzem verbalmente sugerindo a experiência, enfatizando, detalhando, chamando atenção para cada contato realizado pelo corpo: com uma árvore, com a terra, com outra pessoa. $\mathrm{O}$ facilitador, em geral, sugere aos participantes imagens mentais a partir de ou associadas a determinado contato realizado pelo corpo, que remetam a um estado de intimidade e conexão com a Terra. O propósito das vivências em ecologia profunda é facilitar que sejam sentidas e experienciadas suas formulações teóricas em vez de apenas validá-las por meio do intelecto.

Rev. Nufen: Phenom. Interd. | Belém, 9(2), 75-90, mai. - ago., 2017 


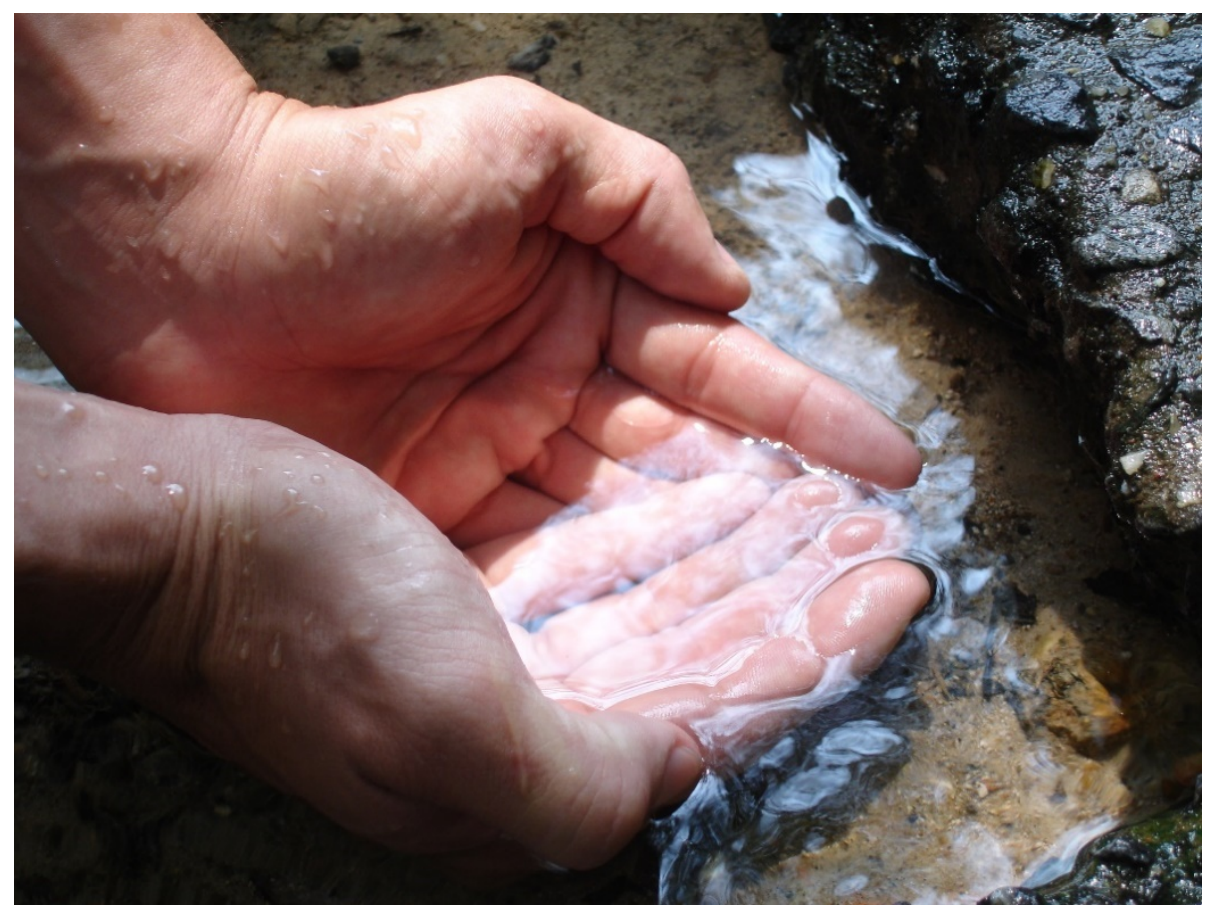

Figura 1: Água na concha da mão.

Fonte: Arquivo pessoal da autora.

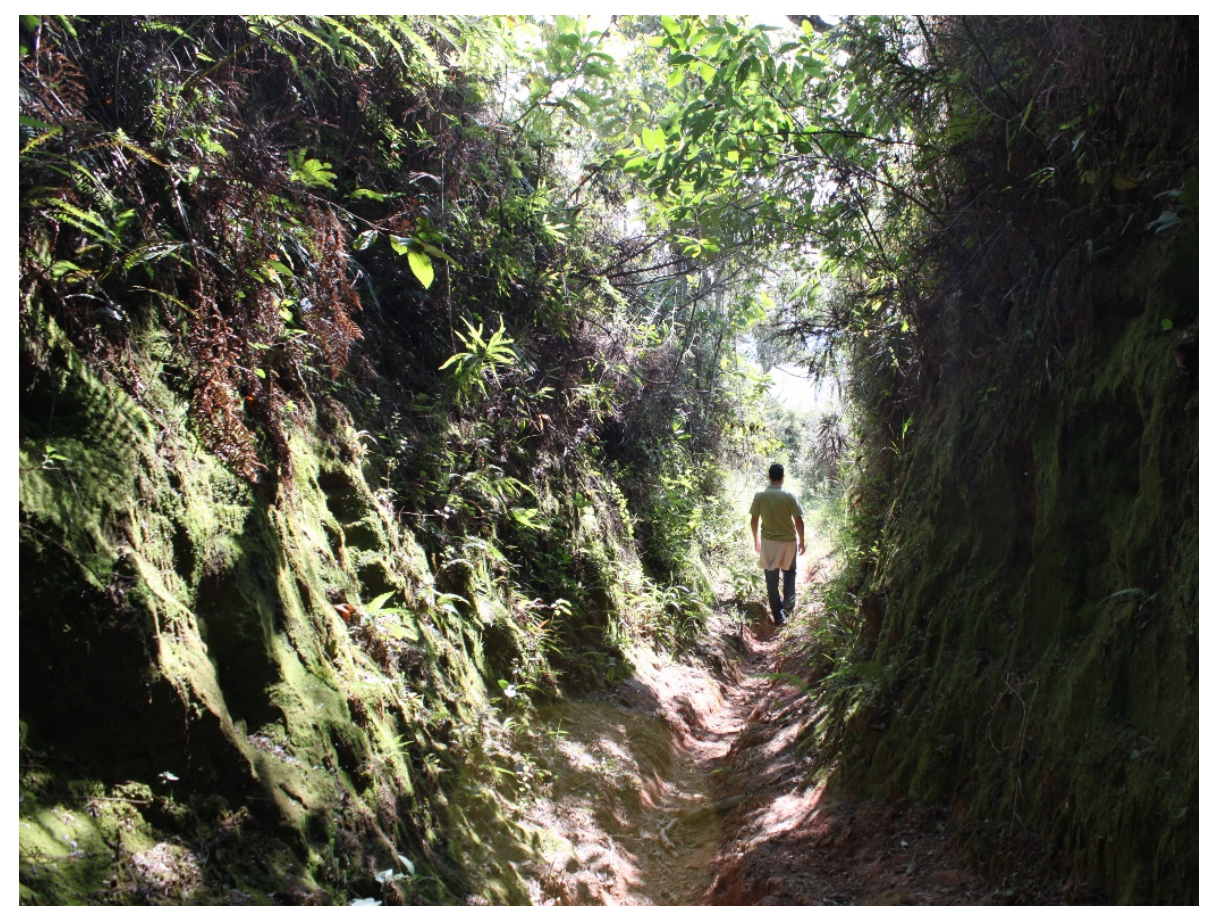

Figura 2: O bosque.

Fonte: Arquivo pessoal da autora. 


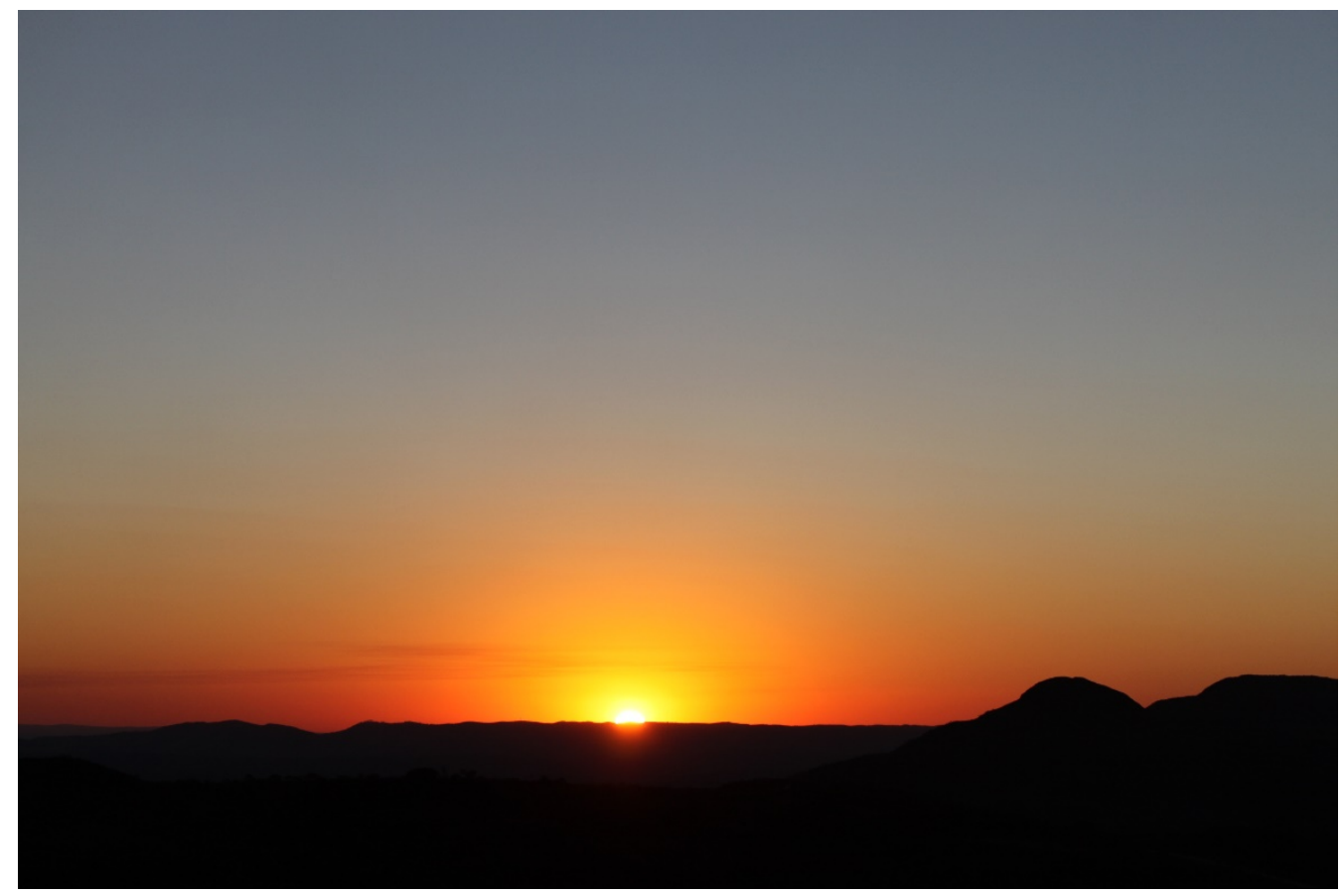

Figura 3: Ocaso.

Fonte: Arquivo pessoal da autora.

Uma experiência sensível é aquela que se dá com mediação dos sentidos, por meio do corpo; pressupõe ser afetado pelo encontro com algo (De Paula, 2015, p. 59). Logo, a vivência em ecologia profunda propõe a experiência de sentir as noções por ela postas como princípios, a saber, de modo sintético: o valor intrínseco de todos os seres, sua conexão, a interdependência e a unidade entre os fenômenos, e o sentido de teia, como impossibilidade de cada elemento existir à parte, isoladamente. Não significa dizer que, quando da proposição da ecologia profunda, primeiro foram postas as noções para em seguida serem experienciadas - o que aconteceu foi exatamente o inverso: as noções foram postas com base na experiência. Isto é, a ecologia profunda surgiu como uma proposição crítica ao modo como a ecologia vinha predominantemente construindo suas reflexões e firmando suas bases: uma maneira compartimentada de analisar os fenômenos e que desconsiderava as experiências sensíveis dos pesquisadores. O resultado era uma ecologia cujos preceitos apontavam para o distanciamento entre o homem e a Terra, colocando-o em posição de domínio, e esta, como bem utilitário.

Como exemplo desta inquietação crítica à ecologia rasa (como é chamada pelos estudiosos a ecologia que não é a profunda), examinemos relatos de um estudioso da ecologia profunda, Stephan Harding. Harding (2008) inicia o primeiro capítulo de sua principal obra da seguinte maneira: "Nosso mundo está em crise e, lamentavelmente, nosso modo de fazer ciência no Ocidente tem inadvertidamente contribuído para os inúmeros problemas que enfrentamos" (p. 21). Ainda no início de sua obra, o autor relata sua experiência em um bosque onde fora certa vez para descansar e vira pegadas no chão que 
Ihe despertaram curiosidade, fazendo-o esconder-se para observar e esperar a sorte de avistar o animal dono daquelas pegadas. No crepúsculo, um minúsculo cervo saltou dentre as árvores. "Na presença daquele ser", conta Harding (2008, p. 22), "um senso profundo da inexprimível beleza da natureza deslizou sobre mim como tênue fumaça, envolvendo-me numa sensação de paz intensa e felicidade". Após esta experiência, Harding, que até então não tivera contato com a ecologia profunda, definiu como tema de sua pesquisa de doutorado a ser desenvolvida no departamento de ecologia da Universidade de Oxford, a ecologia e o comportamento do muntjac (o minúsculo cervo que avistara no bosque). Examinemos o relato de Harding sobre sua experiência durante sua pesquisa para o doutorado:

O trabalho era difícil. Entre outras coisas, eu tinha de realizar um levantamento quantitativo, sistemático, da vegetação do bosque de modo a estudar as preferências do muntjac com relação ao habitat. Esse trabalho levou dois verões e um inverno, isolando centenas de lotes temporários de cinco metros quadrados com varas de bambu e barbante, e depois avaliando a olho a cobertura de várias espécies de ervas e arbustos dentro deles. As árvores tinham de ser medidas usando uma técnica diferente, que consumia tempo. A concentração exigida para extrair esses números do mundo vivo era muito intensa e extenuante, e não parecia natural. Após trabalhar em dois ou três lotes, precisando dar uma folga à minha mente cansada, eu me recostava numa árvore olhando para o céu através do maravilhoso e selvagem emaranhado de galhos, ouvindo o bosque viver sua vida, como um imenso ser que respirava. Tornava-me parte desse ser, com seus galhos se agitando, o canto cruzado dos pássaros e os invisíveis muntjacs levando adiante suas estranhas vidas por toda parte à minha volta. / Durante esses momentos meditativos havia uma percepção profundamente benéfica do bosque Rushbeds como uma inteligência viva e integrada, uma percepção que se expandia para além do próprio bosque, incluindo os atributos vivos do mundo mais vasto da atmosfera, dos oceanos e de todo o corpo do mundo que girava. Nesses momentos, de uma maneira perfeitamente clara e óbvia, o bosque Rushbeds parecia estar vivo, ter sua personalidade singular e poder comunicativo. Esses períodos de comunhão eram intensamente agradáveis e relaxantes, contrastando nitidamente com o esforço estressante para reduzir o bosque a índices quantitativos em minhas cada vez mais numerosas anotações de campo. Reparei com interesse que a prazerosa sensação de união desaparecia no fundo da minha consciência assim que eu começava a coleta de dados. Coligir números entorpecia a mente; existir e respirar com o bosque 
Rushbeds a libertava. [...] Durante meus períodos de descanso eu apenas me sentava entre os muntjacs sem coletar absolutamente qualquer dado. Gostava particularmente de encontrar um animal que estivesse ruminando. Sentado a uma distância respeitosa, eu sentia o prazer intenso, tranquilo, que parecia emanar do pequeno animal quando um bolo de comida ia inchando pelo seu esôfago em direção à boca. Gostava dos olhos semicerrados, da tranquilidade meditativa e da sensação quente, deliciosa, tipo pelo de camurça, que fluía deles como o aroma de uma flor ricamente perfumada. Era como se uma suave luz amarela emanasse deles para os arredores. Meu próprio corpo animal recolhia alguma coisa da descontração e conforto com que viviam suas vidas, como se estivessem passando aos meus sentidos informações sobre um tipo de contentamento que eu não conhecera antes. / Faz agora mais de vinte anos desde que eu realizei esse trabalho e, olhando para trás, percebo que também aprendi, e que possivelmente aprendi mais pela simples exposição das sensações de meu organismo ao bosque Rushbeds e aos muntjacs que pela coleta de dados e pela análise em que estava empenhado para ganhar meu doutorado. Naturalmente, analisar os dados e descrever os resultados não deixaram de ser tarefas agradáveis que exercitaram minha mente racional e permitiram que eu me tornasse membro credenciado da comunidade científica. A ciência também me permitiu preparar um fascinante relato, com base factual, da vida dos pequenos cervos, que seria impossível realizar de qualquer outra maneira. Mas o aprendizado que acabou me proporcionando as lições mais valiosas sobre a natureza veio dos inesperados atributos que me foram revelados pelo bosque Rushbeds e pelos muntjacs ruminando serenamente no Whipsnade. I Para minha intensa decepção, não houve lugar para uma exploração desses atributos na volumosa tese doutoral que finalmente apresentei, pois eles seriam considerados apenas como minhas impressões subjetivas. Eram adequados talvez para a poesia, mas não pertenciam a um modo de fazer ciência que queria me banir para um mundo sem alma de fatos áridos, desprovidos de um significado inerente (Harding, 2008, p. 24-26).

Em seguida, o autor questiona: "E se o que eu tinha experimentado fosse de fato real, poderia algum dia tornar-se parte da ciência?" (Harding, 2008, p. 27). Indagação que nos remete às formulações críticas à ciência apontadas por Edmund Husserl, em meados do século XIX, quando da proposição da fenomenologia. Pois, como algo que se experimenta pode não ser real? Sendo real, por que ser banido da ciência? Pois, se banido for, a ciência afasta-se do mundo-vivido para firmar-se em suposições abstratas. 
A ecologia profunda traz para si experiências como esta relatada por Harding, nascidas da relação do ser-no-mundo com a Terra, e produtoras de sensações e percepções peculiares. Nos relatos de tais experiências, habitualmente aparecem expressões e termos como: inexprimível, beleza, paz intensa, felicidade, tornar-se parte, empatia, expansão, grandeza, encantamento, tudo parece estar vivo, comunhão, intensidade, prazer, união, liberdade, tranquilidade, contentamento, sentimento incapaz de se nomear e se comunicar. São sensações de arrebatamento, expansão do ser, percepção da inteligência viva da Terra, e conexão, que a ecologia profunda traduziu para as noções de teia, de interdependência e unidade. Sensações que parecem não caber em termo algum, daí o fato do emprego recorrente dos termos "inexprimível", "indescritível" e “inexplicável”.

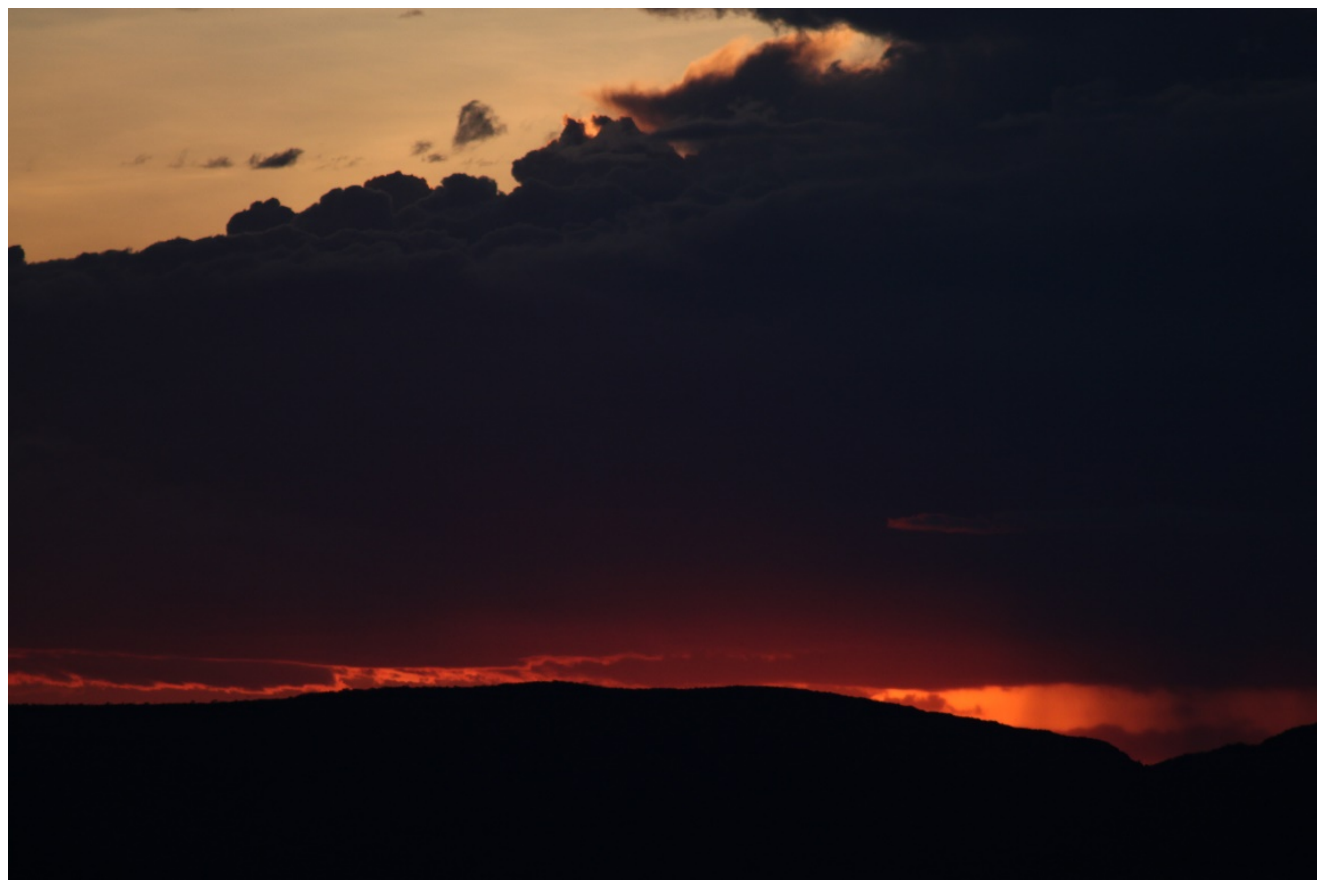

Figura 4: Ocaso em chamas.

Fonte: Arquivo pessoal da autora.

De onde brotam essas sensações? Esse estado do ser-no-mundo em que se experimenta em expansão e intensidade o significado dessa sua condição, como surge? Essa experiência sensível de ser parte de uma teia de relações, qual sua origem? De onde brotam as sensações dessa experiência que produz, pelos sentidos, a percepção de unidade com todos os seres-no-mundo e evidencia pelo corpo a intimidade visceral entre o homem e a Terra, em seu sentido mais amplo, e que é capaz de realizar este fato?

Essas sensações brotam não da Terra, nem do homem, mas do encontro entre ambos. A partir das experiências e leituras realizadas até o presente momento desta investigação, minha hipótese é a de que o lugar de onde brotam tais sensações é o fundo 
escuro apresentado por Dardel (2011), entendido aqui não como atributo da Terra, mas da relação homem-Terra, ou, como explicou De Paula (2015, p. 63), da nossa condição CorpoTerra, esta condição ontológica, inalienável da nossa existência (De Paula, 2015, p. 52).

Pois, questiona a autora, "[...] como é possível falar de Terra sem falar de nossos corpos? Como seria possível conceder à Terra atributos (obscuridade, sentido, língua) que sejam independentes do nosso corpo?" (De Paula, 2015, p. 62). Continua a autora, explicando que

Para compreender a condição Corpo-Terra, é preciso atentar que não existe corpo que não seja sensível e que nós só sabemos isso que chamamos de corpo, que chamamos de indivíduo, porque ele é sensível à Terra. [...] Atavicamente, nós sabemos que somos um corpo porque o corpo realiza a sensibilidade e nessa realização, por exemplo, quando ponho a mão na maçã, o que tenho não é apenas o conhecimento tátil da maçã, o que tenho, também, é o saber de que sou a mão que toca a maçã. Logo, a todo instante o corpo nos atualiza de nossa própria existência porque nos atualiza sobre a Terra, porque sentimos a Terra. Nessa medida, nós não só sentimos a Terra, nós somos a Terra (De Paula, 2015, p. 62).

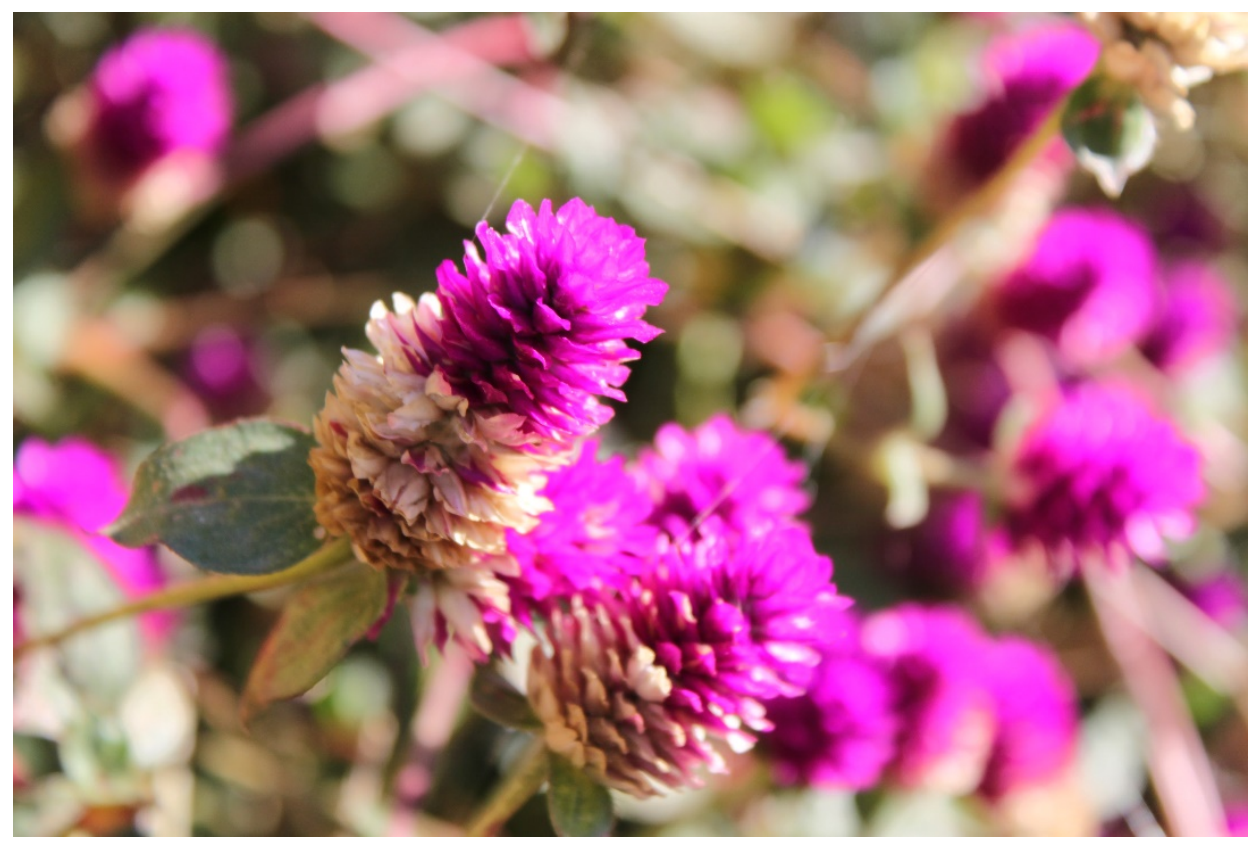

Figura 5: Sempre-vivas.

Fonte: Arquivo pessoal da autora. 


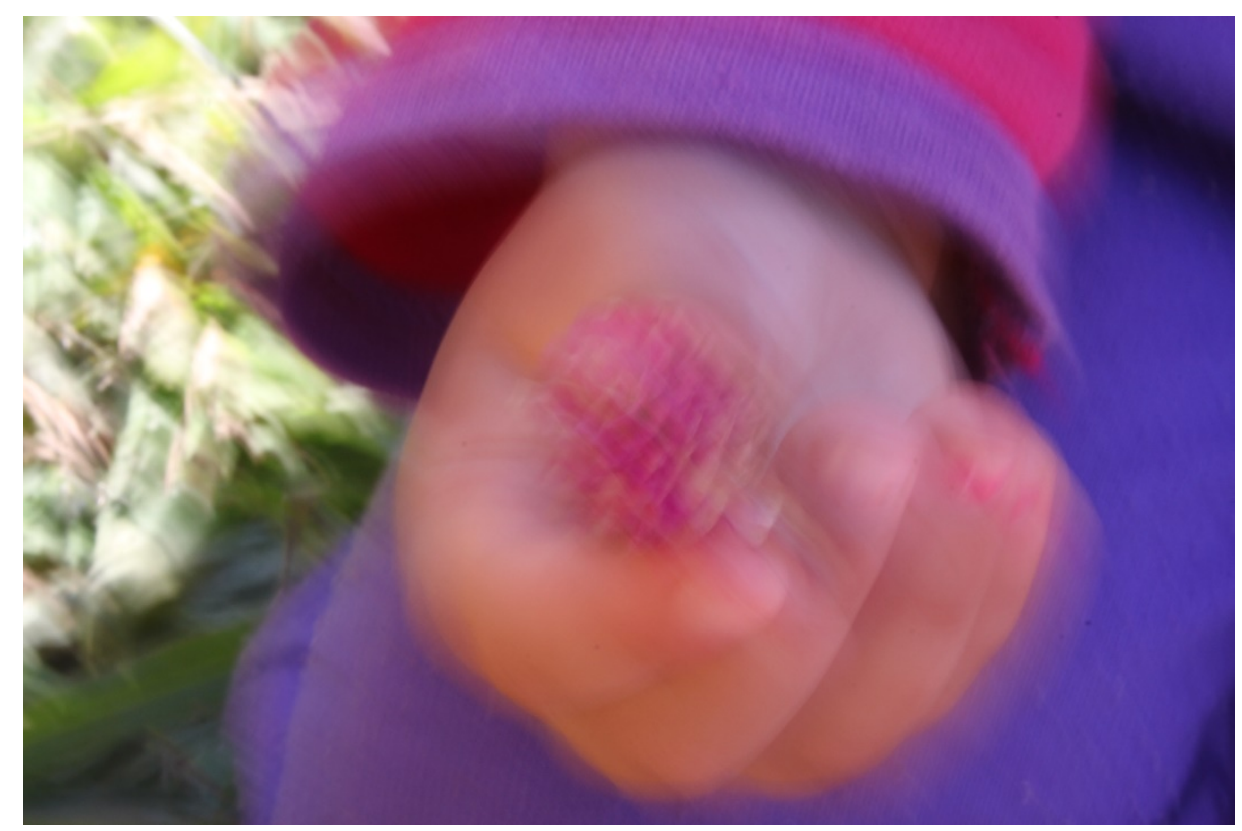

Figura 6: A descoberta.

Fonte: Arquivo pessoal da autora.

Portanto, "[...] tanto corpo quanto Terra só são (existem, se realizam, são compreensíveis) na relação entre eles (nunca como elementos separáveis) " (De Paula, 2015, p. 64).

Entendo, então, que as sensações produzidas em uma experiência ou vivência em ecologia profunda têm origem no fundo escuro próprio da nossa condição Corpo-Terra, lugar obscuro que é tocado quando da interação íntima entre o homem e a Terra. Temos, aqui, uma aproximação entre a experiência em ecologia profunda e o acontecimento geopoético, descrito por De Paula (2015) como "[...] aquele momento súbito, oriundo do encontro entre homem e lugar, onde sofremos vertigem, catarse, encanto ou angústia" ( $p$. 52). Trata-se de um encontro entre o homem e a Terra capaz de produzir sensações traduzidas em termos como encanto, obscuridade, vertigem, felicidade, intraductibilidade, angústia, inexprimível, arrebatamento, alegria (De Paula, 2015, p. 59). De Paula (2015) destaca que "O acontecimento geopoético se realiza na nossa sensibilidade em relação à Terra" (p. 59), o que equivale a dizer que "[...] todo acontecimento geopoético pressupõe uma situação: um indivíduo-sensível-ao-lugar. E essa situação se realiza via corpo" (De Paula, 2015, p. 60).

Mas tais sensações não brotam a todo tempo, em todo encontro. As vivências em ecologia profunda, por exemplo, costumam produzir sensações de bem-estar, mas nem sempre sensações intensas e inexprimíveis de arrebatamento, expansão, unidade e paz. Este fato pode ser atribuído ao que Merleau-Ponty (1994) chama de "Eu Anterior", o qual se constitui antes do pensamento, e é uma "modalidade do corpo que se rende ao convite do 
lugar", isto é, "sem que tomemos a decisão, ele já agiu" (De Paula, 2015, p. 61). Por exemplo, "os olhos", explica De Paula (2015), "sem que decidamos, acompanham o movimento de algo; quando penso em comer a fruta, minha mão já está pegando-a, sem que eu formule nenhum comando consciente" (p. 61). Refletindo acerca do acontecimento geopoético,

De Paula (2015, p. 61) afirma que nessa situação o Eu Anterior nos toma por inteiro e fixa-nos em um estado em que racionalidade e conhecimentos prévios são suprimidos. Daí o caráter súbito do acontecimento geopoético, daí o motivo de as sensações inexprimíveis não brotarem a todo tempo, em todo e qualquer encontro do homem com a Terra, nem em toda experiência em ecologia profunda. Como num susto, numa surpresa, somos arremessados ao vigor do encontro íntimo com a Terra, tocando o fundo escuro promotor de sensações indizíveis.

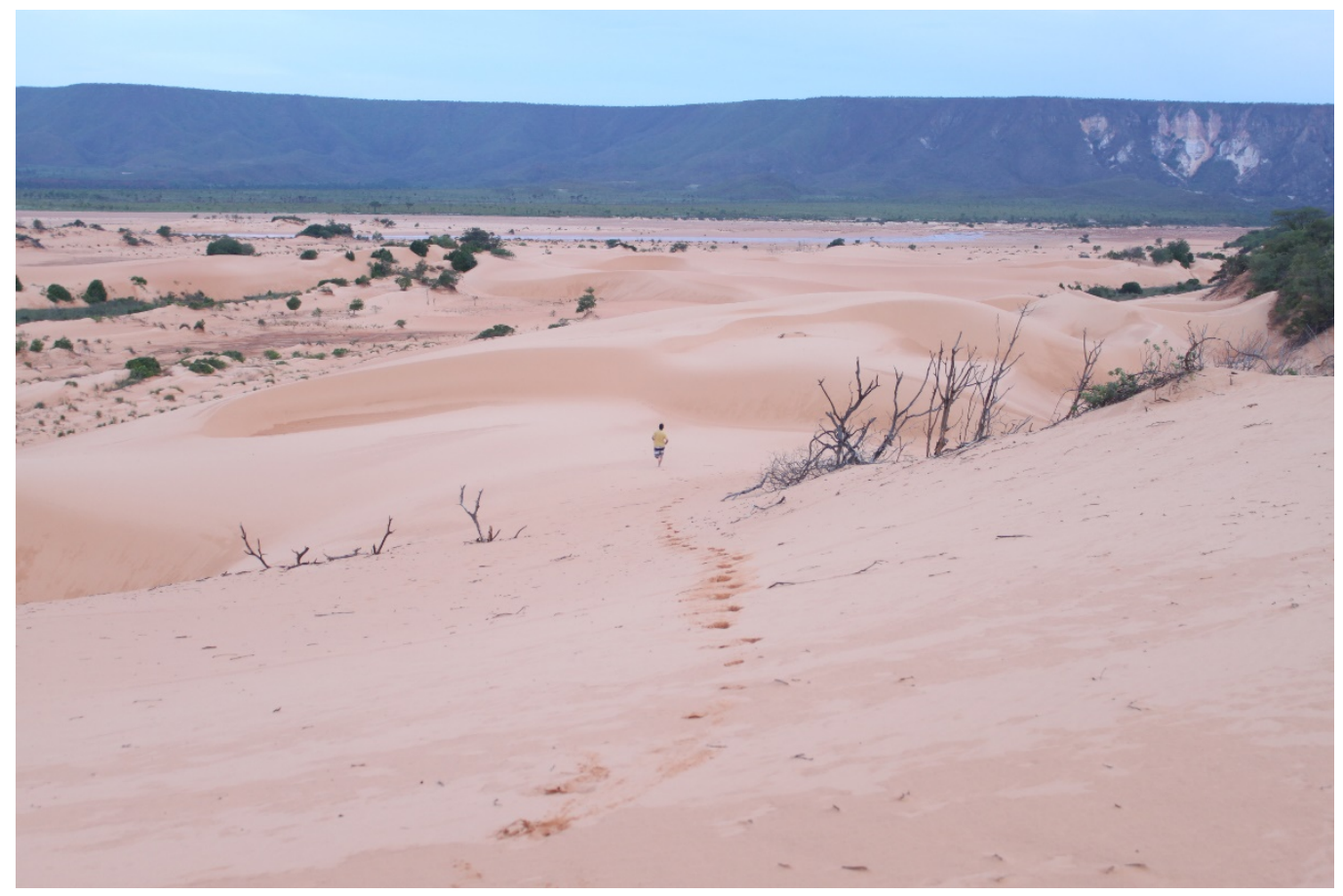

Figura 7: O ínfimo.

Fonte: Arquivo pessoal da autora. 


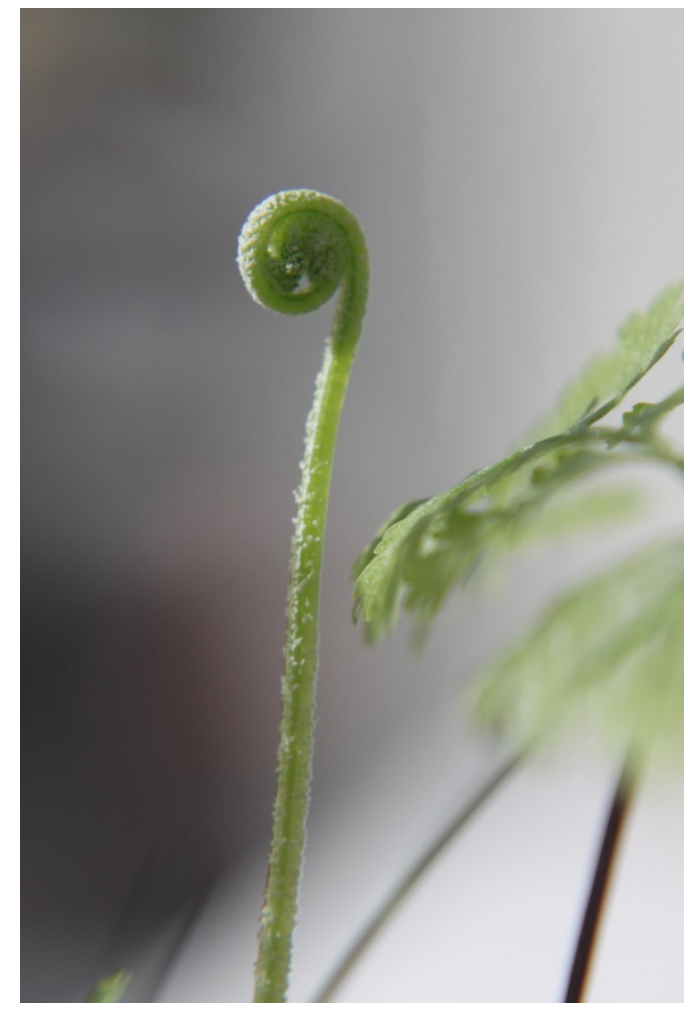

Figura 8: Devir.

Fonte: Arquivo pessoal da autora.

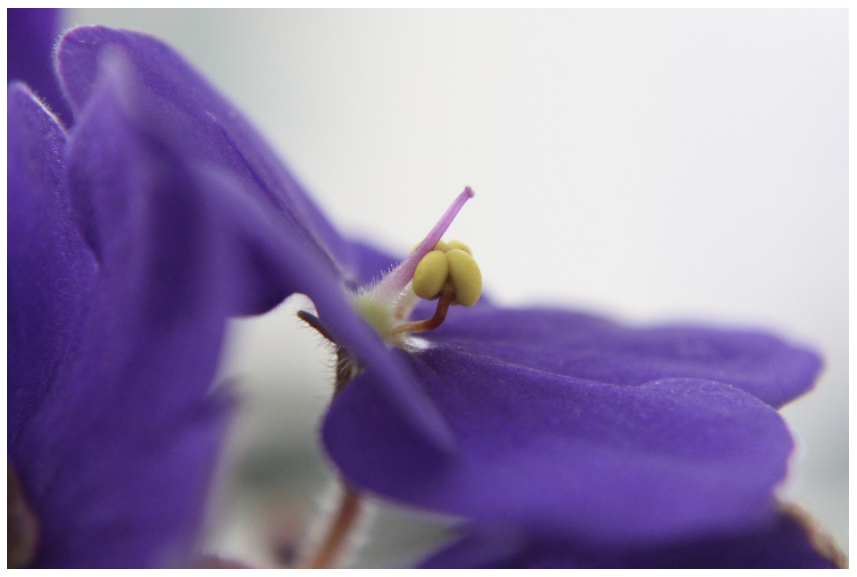

Figura 9: Violeta.

Fonte: Arquivo pessoal da autora.

Esta abertura investigativa da aproximação entre a vivência em ecologia profunda e o acontecimento geopoético, dá-se na medida em que as sensações produzidas em ambas as experiências têm origem no fundo escuro próprio de nossa condição CorpoTerra, lugar obscuro inexprimível que é tocado quando da interação íntima entre homem e Terra, daí a semelhança entre os termos empregados na descrição de tais experiências. Se, para De Paula (2015, p. 57), o acontecimento geopoético brota do fundo escuro da nossa condição Corpo-Terra, é este também o lugar a ser tocado para se acessar a consciência 
proposta pela ecologia profunda. O fundo escuro tem a qualidade de acionar a memória sobre a inegável conexão visceral e existencial entre o homem e a Terra. Em outras palavras, tal conexão é, simples e incondicionalmente, independente de conhecê-la ou sentila, e o fundo escuro atua como que o levantar do véu suavemente disposto sobre a experiência da referida conexão. Vivência em ecologia profunda e acontecimento geopoético aproximam-se, ainda, pois em ambos o corpo é via de acesso, são experiências fundamentalmente sensíveis. O que temos em ambos, na vivência da ecologia profunda e no acontecimento geopoético, é o encontro do ser-no-mundo com a Terra produzindo sentimentos inexprimíveis.

A abordagem da qual se vale a ecologia profunda acerca-se da fenomenologia, de modo que o estudo da ecologia profunda ganha densidade e profundidade quando relacionado com reflexões e conceitos de base fenomenológica, visto que estes encontramse, atualmente, mais explorados e do que os estudos em ecologia profunda centrados na experiência.

\section{ECOLOGIA PROFUNDA: EXPERIÊNCIA, E NÃO PLATAFORMA AMBIENTALISTA}

Para apresentar algumas considerações finais, reporto-me ao texto Deep Ecology de Michael Nelson (2008), ecologista norte-americano e professor de filosofia ambiental. No referido texto, o autor apresenta e discute a ecologia profunda, tecendo críticas sobretudo quanto aos princípios de biocentrismo e igualitarismo, que propõem que os valores intrínsecos de cada espécie viva da natureza são equivalentes, não devendo, portanto, nenhuma espécie ser subjugada a outra, contrariando, assim, noções antropocêntricas (Nelson, 2008). A esse respeito, Nelson (2008) discute a impotência da ecologia profunda enquanto teoria ética ambiental, e cita o filósofo Bryan Norton: "The 120,000th elk cannot be treated equally with one of the last California condors - not, at least, on a reasonable environmental ethic"1 (Norton, 1991, p. 224 citado por Nelson, 2008, p. 208). Outro aspecto discutido por Nelson (2008) é o que ele se refere como holismo metafísico ("metaphysical holism"), que, de acordo com o autor, permitiu aproximações da ecologia profunda com algumas religiões e a espiritualidade New Age.

One can apprehend ontological interconnectedness through enlightenment or "self-realization" (Devall and Sessions 1985, pp. 67-69; Naess 1987). As Fox says, "It is the idea that we can make no firm ontological divide in reality between the human and the nonhuman realms. ... [T]o the extent that we perceive

\footnotetext{
${ }^{1}$ Em livre tradução minha: $\mathrm{O} 120.000^{\circ}$ alce não pode ser tratado da mesma maneira que o último condor da Califórnia - pelo menos não por uma ética ambiental razoável (NORTON, 1991, p.224 apud NELSON, 2008, p.208).
} 
boundaries, we fall short of deep ecological consciousness" (Fox 1984, p. 196). Through this awakening, the ontological boundaries of the self extend outward, incorporating more and more of the lifeworld into the self. This insight discloses that there is in reality only one big Self, the lifeworld, a notion developed in the article "The World Is Your Body" (Watts 1966). This method of self-realization is identification: By recognizing the intrinsic worth of other living beings, one recognizes the solidarity of all life forms ${ }^{2}$ (Nelson, 2008, p. 207).

Segundo Nelson (2008), pesquisadores apontam que há uma tensão insolúvel entre o igualitarismo biocêntrico e o holismo metafísico dentro dos valores do sistema ecológico. E Rothenberg (1996 citado por Nelson, 2008, p. 210), provavelmente referindo-se aos Oito Princípios ${ }^{3}$ firmados como plataforma pela ecologia profunda, apontou-a como um conjunto de dicas sobre a relação entre cultura e natureza.

Considero que o igualitarismo a que se refere a ecologia profunda vai além da interpretação de que todos os seres possuem o mesmo valor intrínseco no sentido discutido por Nelson (2008), que vai ao encontro do ambientalismo e da ética ambiental. Entendo que o proposto pela ecologia profunda é experienciar, sentir a conexão, o entrelace e a interdependência dos seres enquanto fenômenos - e não isolados. Que o ponto principal é propor a experiência de um fenômeno para, a partir dela, despertar a percepção para o fato de que tudo existe em relação. Aí reside a essência do igualitarismo defendido pela ecologia profunda. O sentido da igualdade de valor dos seres acontece pois todos participam para que haja o fenômeno da interação, a teia de relações conectadas e imbricadas, condição para que exista o mundo-vivido. Em outras palavras, o valor é igualitário no sentido de tudo existir apenas em relação a. Pode-se apontar que este raciocínio se aplica também a coisas inanimadas, enquanto que a ecologia profunda se refere apenas a seres vivos. Sim. O fato de apenas existir em relação a algo é válido também para coisas inanimadas, porém, estas não possuem o mesmo valor intrínseco de um ser vivo pois não são indispensáveis para a vida como o são os elementos da Terra.

Compreendo a ecologia profunda como uma experiência, e não como proposta de um conjunto de preceitos e paradigmas para compor um método para uma nova ética de

\footnotetext{
2 Em livre tradução minha: Pode-se apreender a interconexão ontológica através da iluminação ou "autorealização" (Devall e Sessions, 1985, pp. 67-69, Naess, 1987). Como diz Fox: "É a idéia de que não podemos fazer uma divisão ontológica firme na realidade entre os reinos humanos e não humanos. [...] Na medida em que percebemos fronteiras, ficamos aquém da profunda consciência ecológica "(Fox, 1984, p.196). Através desse despertar, as fronteiras ontológicas do eu se estendem para fora, incorporando cada vez mais o mundo da vida ao eu. Essa visão revela que na realidade existe apenas um grande Eu, o mundo da vida, uma noção desenvolvida no artigo "O Mundo É Seu Corpo" (Watts, 1966). Este método de auto-realização é a identificação: Ao reconhecer o valor intrínseco de outros seres vivos, reconhece-se a solidariedade de todas as formas de vida. (Nelson, 2008, p.7).

${ }_{3}^{3}$ Oito princípios elencados pelos propositores da ecologia profunda, Arne Naess e George Sessions, em 1984, como síntese de suas propostas.
} 
ambientalismo. Possui caráter ontológico e atua no nível da experiência do ser-no-mundo, avançando além de ser método para uma ética ambiental, abarcando o intuito de fundar no ser-no-mundo uma percepção a partir da experiência sensível. Experiência que pode ser entendida pela fenomenologia da percepção a partir de nossa condição Corpo-Terra, e manifesta pelo fundo escuro. A vivência em ecologia profunda aproxima-se da intenção de tocar o fundo escuro - termo apresentado por Dardel (2011) que comunica o lugar de onde brotam sensações inexprimíveis no encontro entre o homem e a Terra.

Nesse sentido, em última instância a ecologia profunda influenciará sim em uma nova ética ambiental e no ambientalismo, mas não apenas isso, pois, ao fundar uma percepção do mundo-vivido a partir de uma experiência sensível da relação intrínseca dos fenômenos da Terra, esta é agregada nos modos de manifestação e expressão do ser-nomundo - entendimento, pensamentos, atitudes. Um planejador ambiental que tenha como base paradigmas que compõem um método para ética ambiental planejará de modo muito distinto daquele que tem como base uma consciência ecológica ampla fundada na experiência direta da interdependência dos fenômenos. Este último pode associar ao seu planejamento os paradigmas do método, mas o primeiro não é capaz de associar a experiência da conexão entre os fenômenos a menos que ele a viva.

Portanto, a ecologia profunda constitui-se muito mais como uma experiência do ser-no-mundo, que pode desdobrar-se impregnando modos de relacionar-se e expressar-se daquele ser-no-mundo, nas quais estão incluídas também suas atividades profissionais. Ou

seja, a ecologia profunda não se restringe ao seu campo de origem, a ecologia. É uma experiência existencial que desvela no ser-no-mundo formas de compreender e colocar-se no mundo-vivido.

\section{Referências}

Dardel, E. (2011). O Homem e a Terra: natureza da realidade geográfica. São Paulo: Perspectiva.

De Paula, F. C. (2015). Sobre geopoéticas e a condição corpo-terra. Geograficidade, volume(5), número especial, 30-49. Recuperado de

http://www.uff.br/posarq/geograficidade/revista/index.php/geograficidade/article/view/252 /pdf

Harding, S. (2008). Terra Viva: ciência, intuição e a evolução de Gaia. São Paulo: Cultrix.

Merleau-Ponty, M. (1994). Fenomenologia da percepção. São Paulo: Martins Fontes.

Nelson, M. P. (2008). Deep Ecology. Em J. B. Callicott \& R. Frodeman (Ed.), Encyclopedia of Environmental Ethics and Philosophy, (pp. 206-211). Estados Unidos da América: Gale. 
Zimmerman, M. E. (1986). Implications of Heidegger's Thought for Deep Ecology. The Modern Schoolman, volume(64), issue 1, 19-43. Recuperado de https://www.pdcnet.org/pdc/bvdb.nsf/purchase?openform\&fp=schoolman\&id=schoolman _1986_0064_0001_0019_0043

\section{Notas sobre a autora}

Gabriela Gazola Brandão. Doutoranda do Programa de Pós-graduação em Arquitetura e Urbanismo da Universidade Federal Fluminense, mestre em Arquitetura e Urbanismo pela mesma Instituição e arquiteta urbanista graduada pela Universidade Federal de Minas Gerais. Membro do Grupo de Pesquisa Geografia Humanista Cultural, desenvolve pesquisa associada às temáticas da fenomenologia, paisagem, lugar e o habitar heideggeriano. E-mail: gabibrandao@ymail.com. 